\title{
Heupproblemen bij kleine hondenrassen
}

\author{
Hip problems in small breed dogs
}

\section{Brondeel, D. N. M.Grosjean, E. Bogaerts, E. Coppieters, E. de Bakker, B. Van Ryssen, Y. Samoy}

Vakgroep Medische Beeldvorming van de Huisdieren en Orthopedie van de Kleine Huisdieren, Faculteit Diergeneeskunde, Universiteit Gent, Salisburylaan 133, B-9820 Merelbeke

Yves.Samoy@UGent.be

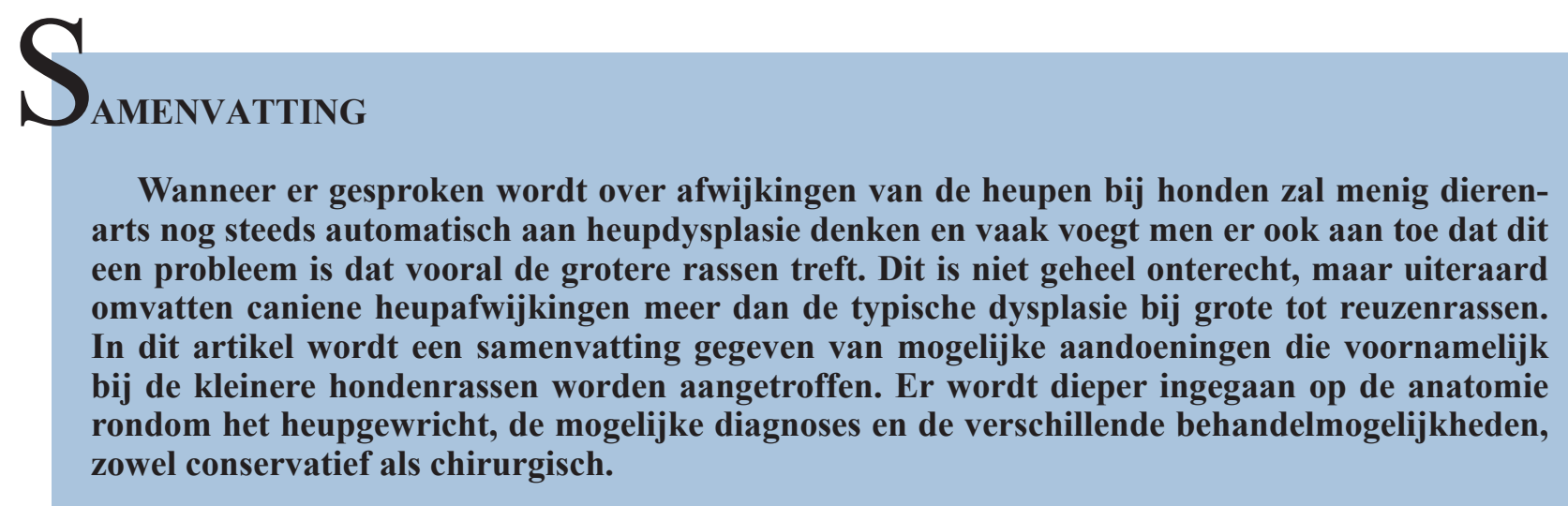

\section{ABSTRACT}

Whenever a discussion arises regarding canine hip problems, many veterinarians will automatically conclude that it's hip dysplasia they are dealing with, often followed by the statement that mostly large breed dogs suffer from this condition. In the literature, this statement is largely confirmed; however, canine hip problems include more than the typical dysplastic joint in large to giant breed dogs. In this paper, the other "usual suspects" are discussed, particularly in small breed dogs. The focus lies on the pelvic anatomy, the possible diagnoses and the treatment options, both conservatively and surgically.

\section{ANATOMIE}

Het heupgewricht is een kogelgewricht dat bestaat uit twee botsegmenten: het caput femoris (convex) enerzijds en het acetabulum (concaaf) anderzijds. Rondom het heupgewricht bevindt zich het gewrichtskapsel dat sterk bijdraagt tot de stabiliteit van het heupgewricht. Tussen het caput femoris en het centrum van het acetabulum bevindt zich het ligamentum capitis femoris. Dit kleine ligament speelt een rol bij de ontwikkeling van de heup en draagt in beperktere mate bij tot de heupstabiliteit. Aan de ventrale zijde van het acetabulum, bevindt zich het ligamentum acetabuli transversus. Dit ligament overbrugt de ventrale rand van het acetabulum en zorgt ervoor dat het heupgewricht niet naar ventraal kan luxeren (Millis en Levine, 2014) (Figuur 1).

Door zijn conformatie is het heupgewricht een zeer mobiel gewricht dat door een ganse resem spieren in

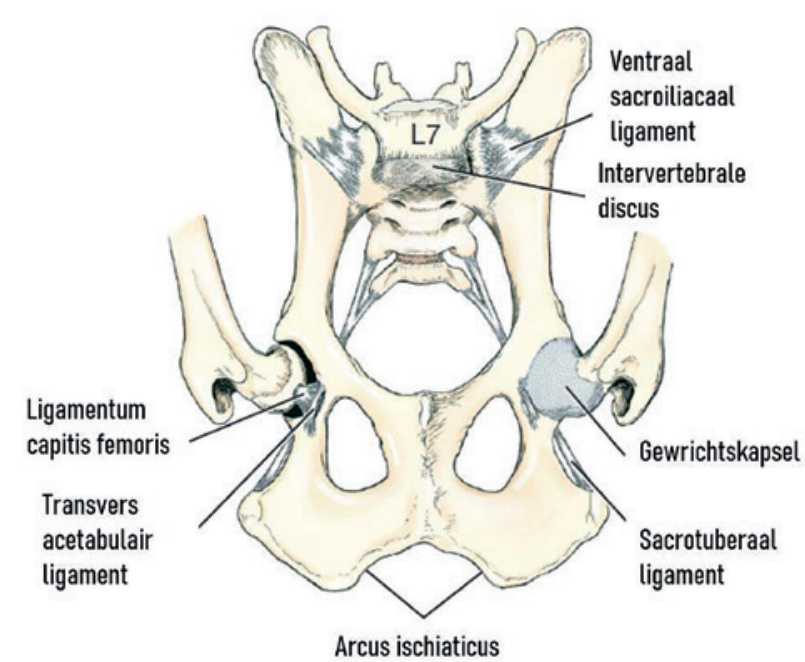

Figuur 1. Ventraal aspect van het bekken met de voornaamste botstructuren en ligamenten (uit: Millis en Levine, 2014). 

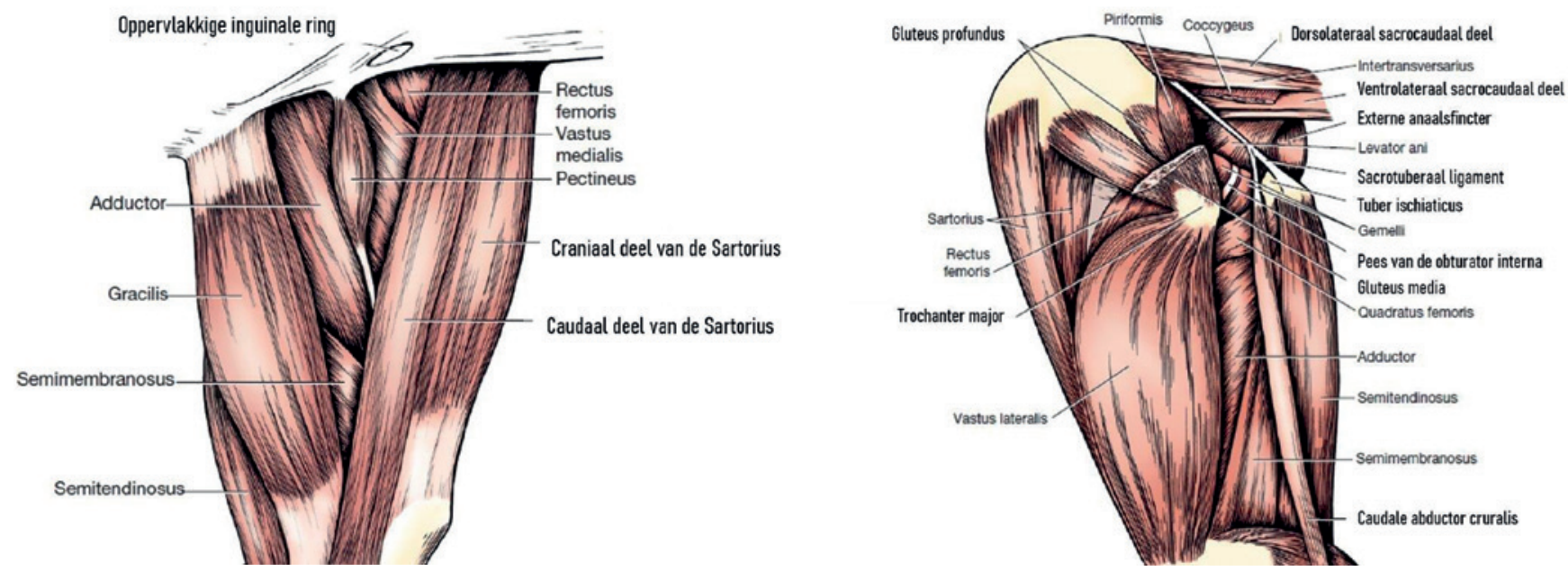

Figuur 2. Mediaal (links) en lateraal (rechts) aanzicht van de heupmusculatuur (uit: Millis en Levine, 2014).
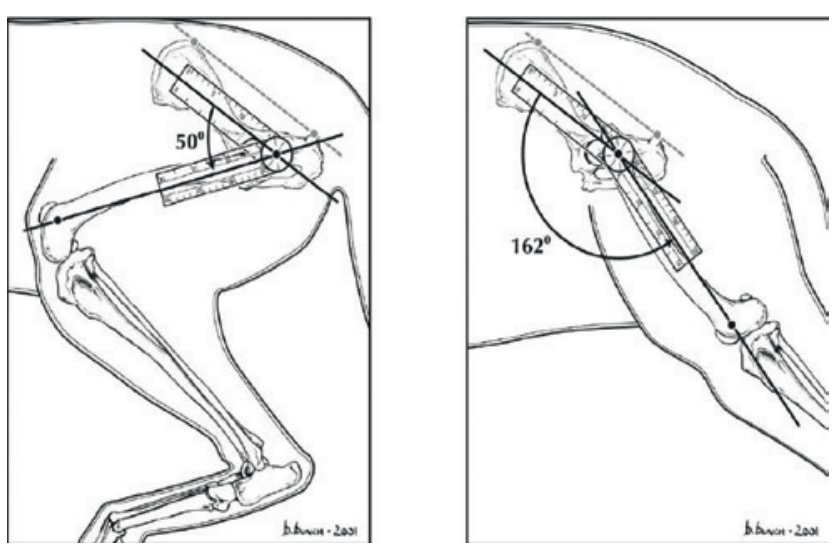

Figuur 3. Plooibaarheid van het heupgewricht (uit: Millis en Levine, 2014).

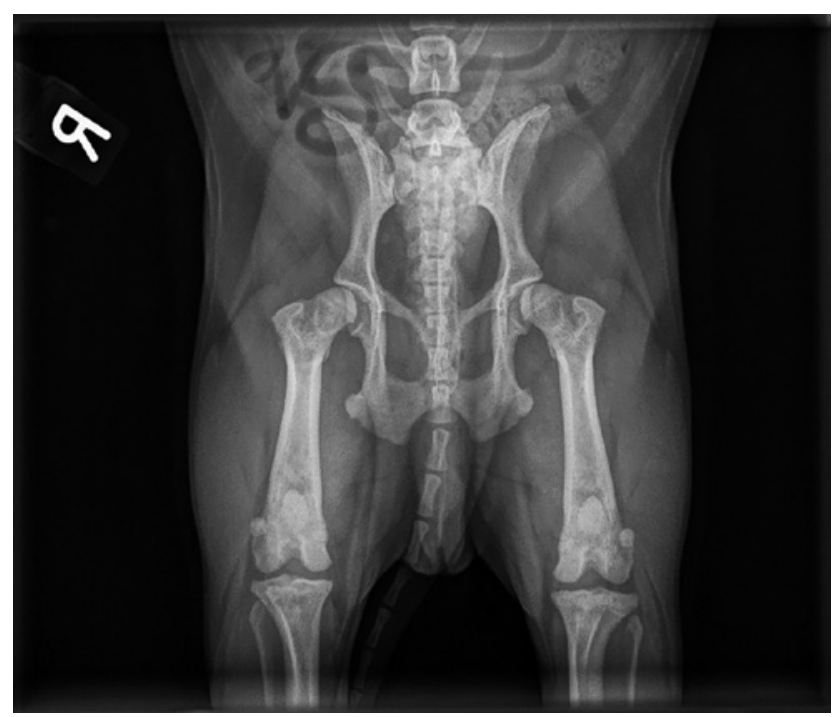

Figuur 4. Radiografische ventrodorsale opname van de heupen van een mopshond van vier jaar oud. Er is bilateraal subluxatie van de heupkoppen zichtbaar met secundaire degeneratieve veranderingen. verschillende vlakken bewogen kan worden. Er kunnen zes soorten bewegingen met elk hun spieren onderscheiden worden (Figuur 2)

- Flexie: M. Iliopsoas, M. Sartorius en de M Tensor Fascia Lata

- Extensie: Mm.Gluteii, M. Semimembranosus, M. Semitendinosus, M Biceps Femoris

- Abductie: M. Gluteus medius

- Adductie: Mm. Adductor longus en brevis en M. Pectineus

- Laterale rotatie: Mm. Obturatorus interna en externa, M. Gemilli

- Mediale rotatie: M. Gluteus Profundus en M. Semitendinosus

De normale beweeglijkheid van de heupen is ongeveer $50-55^{\circ}$ flexie en $160-165^{\circ}$ extensie. Bij een geplooide heup kan het gewricht ongeveer $120^{\circ}$ in abductie en $65^{\circ}$ in adductie gebracht worden. Bij een gestrekte heup is dat $85^{\circ}$ abductie en $63^{\circ}$ adductie. Interne en externe rotatie ligt beide rond de $50-55^{\circ}$ (Millis en Levine, 2014) (Figuur 3).

\section{HEUPDYSPLASIE BIJ KLEINE HONDEN- RASSEN}

Heupdysplasie wordt het meest gezien bij grote en reuzerassen, maar kan in principe bij elk ras voorkomen (Witsberger et al., 2008; Smith et al., 2012). Heupdysplasie werd reeds gediagnosticeerd bij kleine of middelgrote rassen, zoals de Tibetaanse terriër, de standaard- en dwergpoedel, de buldog, de mopshond, de dobermann pinscher, de Lhasa apso, de west highland high terriër, de shih tzu, de pekinees, de dwergkeeshond, de fox terriër, de boston terriër, de yorkshire terriër, de maltezer, de chihuahua, de mini-schnauzer, de beagle en de Amerikaanse cocker spaniël (Martin et al., 1980; Rettenmaier et al., 2002; 


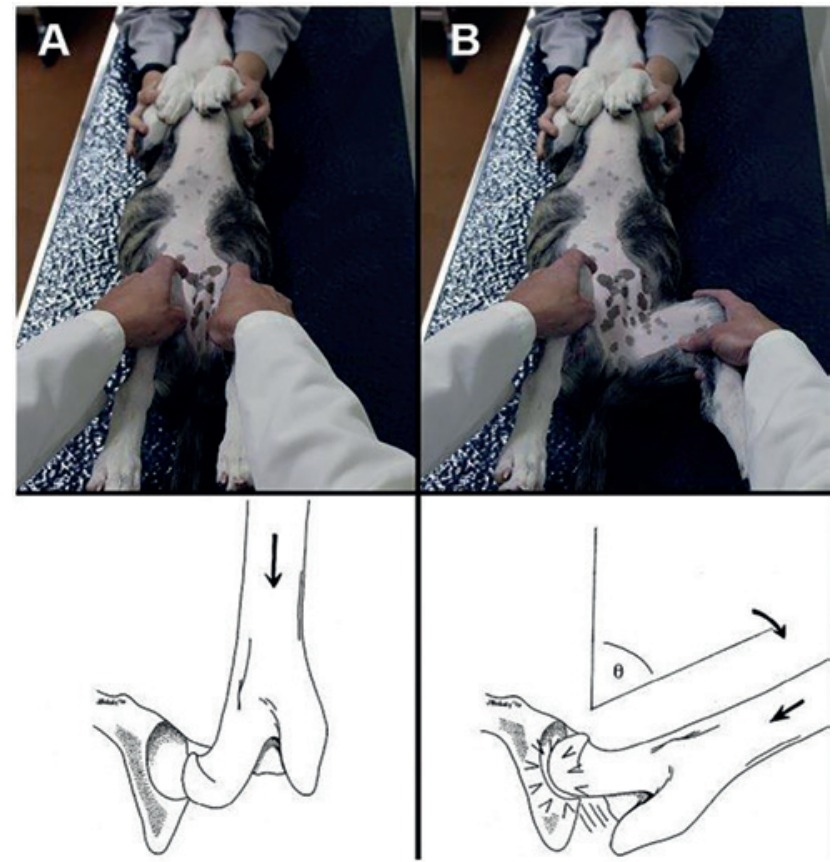

Figuur 5. Het uitvoeren van de Ortolani-test op de linkerheup wordt hier geïllustreerd aan de hand van foto's en bijhorende tekeningen die het effect op het heupgewricht demonstreren. A. Eerst wordt er een neerwaartse druk (pijl) uitgevoerd op de femur, waardoor een subluxatie van de heup veroorzaakt wordt. B. Terwijl de neerwaartse druk (pijl) wordt aangehouden, wordt de heup traag geabduceerd (gebogen pijl) tot een plop gevoeld wordt (uit: Syrcle, 2017).

Coopman et al., 2008; Witsberger et al., 2008; King, 2017). In Tabel 1 wordt een overzicht gegeven van de kleine en middelgrote hondenrassen die in de periode 2017-2019 gediagnosticeerd werden met heupdysplasie of heuplaxiteit bij de vakgroep Medische Beeldvorming en Orthopedie van de Kleine Huisdieren van de Faculteit Diergeneeskunde (UGent). Heupdysplasie veroorzaakt gewrichtsontsteking en secundaire osteoartrose, wat resulteert in verschillende gradaties van discomfort en immobiliteit. Tot op heden zijn de etiologie en pathogenese van deze aandoening nog steeds niet helemaal duidelijk. Er wordt ervan uitgegaan dat heupdysplasie het gevolg is van de interactie tussen multipele genen gecombineerd met bepaalde omgevingsfactoren. Het is duidelijk dat de klinische observatie van heuplaxiteit een sleutelrol speelt in de ontwikkeling van osteoartrose (Smith et al., 2012).

De klinische klachten gerelateerd aan heupdysplasie kunnen opgedeeld worden in twee groepen. De juveniele vorm waarbij de honden op een leeftijd van vijf tot twaalf maanden aangeboden worden met klachten ter hoogte van de achterhand, zoals manken, "bunny-hopping", moeilijk kunnen rechtstaan, niet willen wandelen, geen trappen willen lopen, een klik horen, etc. De klachten worden verondersteld het gevolg te zijn van ernstige heuplaxiteit. De tweede vorm waaronder heupdysplasie zich voordoet en die ook
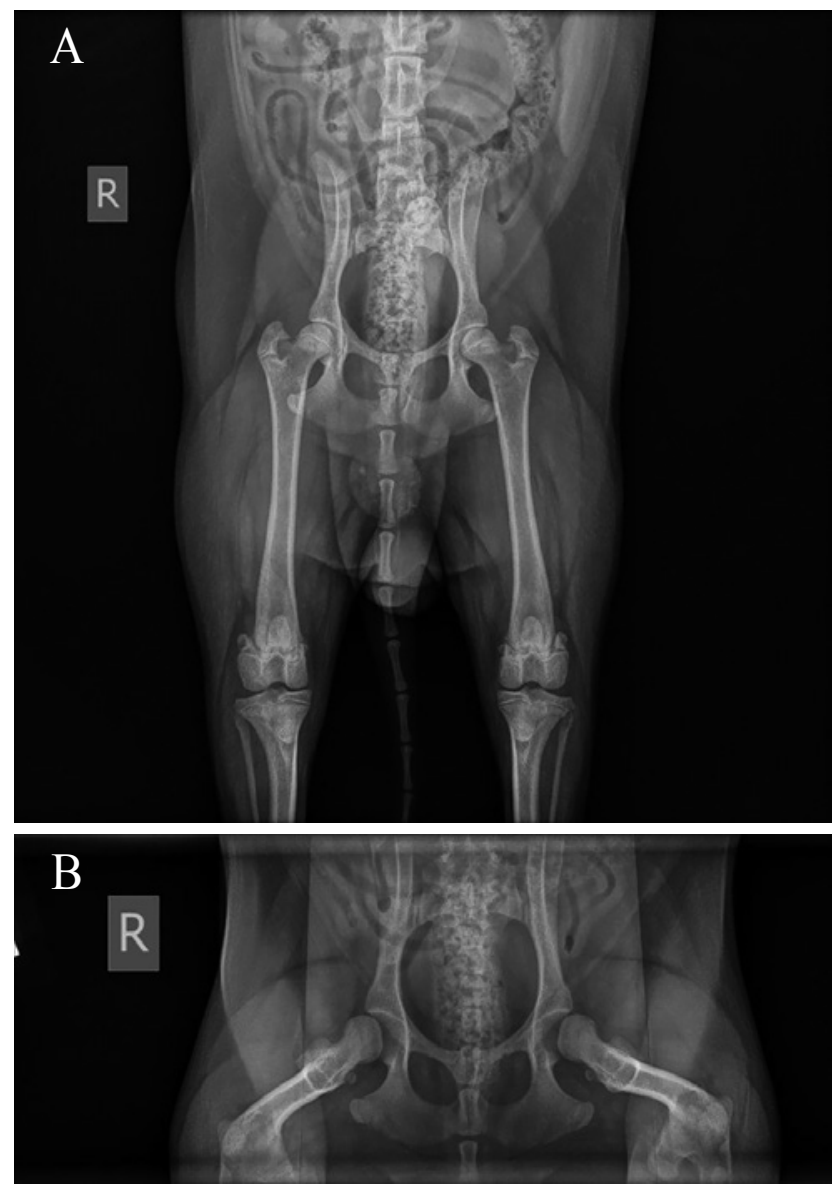

Figuur 6. A. Ventrodorsale radiografische opname van de heupen van een sheltie van acht maanden oud. B. Ventrodorsale distractie-opname (door middel van het "Vezzoni-modified Badertscher distraction device") van dezelfde sheltie waarbij een laxiteitsindex van 0,66 (rechterheup) en 0,81 (linkerheup) werd berekend.

Tabel 1. Overzicht van kleine en middelgrote hondenrassen gediagnosticeerd met heupdysplasie of heuplaxiteit op de Faculteit Diergeneeskunde (UGent) in de periode $2017-2019$.

\begin{tabular}{lcc}
\hline Ras & $\begin{array}{c}\text { Heup- } \\
\text { dysplasie }\end{array}$ & $\begin{array}{c}\text { Heup- } \\
\text { laxiteit }\end{array}$ \\
\hline Beagle & 1 & 1 \\
Canis vulgaris & 2 & 1 \\
Cavalier king charles spaniël & 4 & 1 \\
Corgi & 2 & 0 \\
Dwergkeeshond & 2 & 2 \\
Engelse cocker & 1 & 1 \\
Engelse buldog & 0 & 0 \\
Franse buldog & 4 & 0 \\
Jack russell & 2 & 1 \\
Lhasa apso & 1 & 0 \\
Maltezer & 3 & 0 \\
Mopshond & 3 & 0 \\
Poedel & 1 & 0 \\
Sheltie & 0 & 1 \\
Teckel & 0 & 1 \\
Tibetaanse terriër & 2 & 0 \\
\hline
\end{tabular}




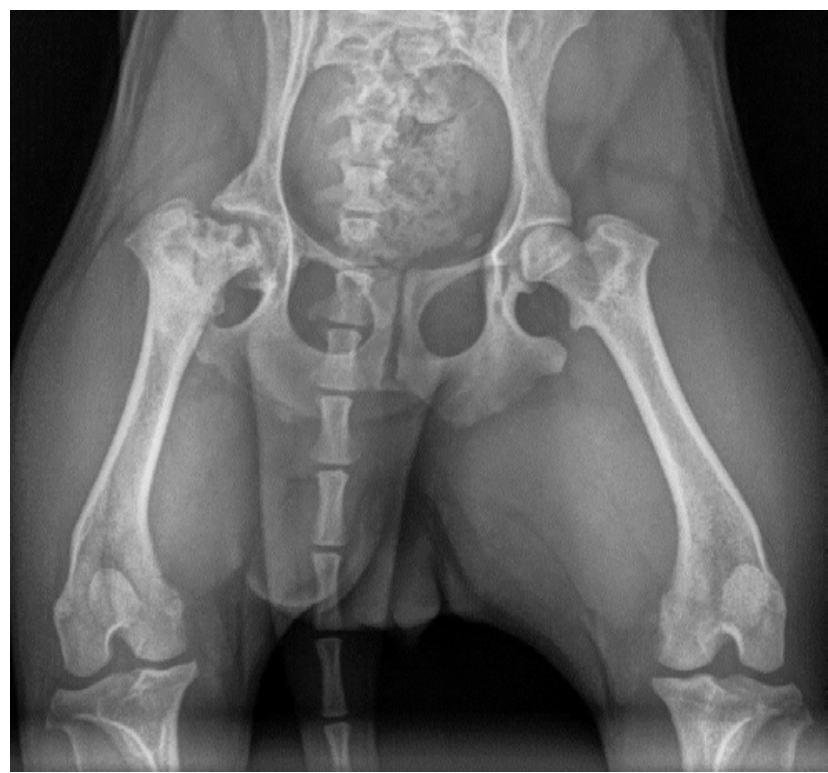

Figuur 7. Radiografisch beeld van een jack russel terriër van tien maanden oud met een Legg-Calvé-Perthes of avasculaire necrose van de femurkop aan de linkerzijde. Bemerk het typische "weggevreten" aspect van de femurkop in vergelijking met de tegenoverliggende zijde.

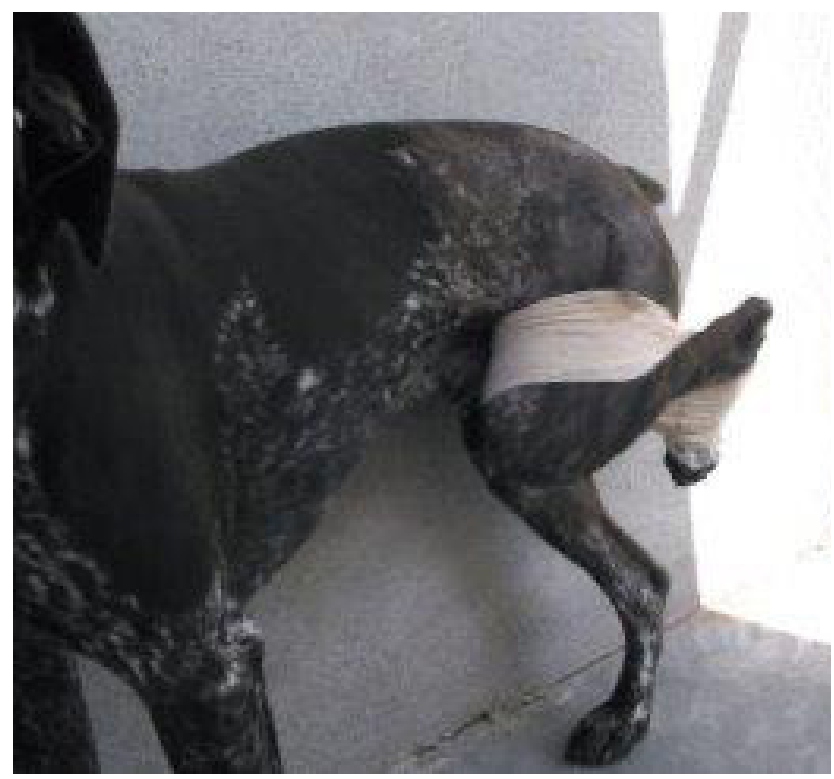

Figuur 8. Een hond waarbij een Ehmersling geplaatst werd na een succesvolle gesloten reductie van een heupluxatie (uit: Moores, 2006).

het meeste voorkomt, is de chronische vorm waarbij de volwassen hond klachten ontwikkeld ten gevolge van secundaire degeneratieve veranderingen (Smith et al., 2012; Syrcle, 2017).

Een grondig klinisch, orthopedisch en neurologisch onderzoek is steeds noodzakelijk om de diagnose van heupdysplasie correct te kunnen stellen en andere aandoeningen met een gelijkaardige klinische presentatie, zoals een kruisbandruptuur, te kunnen uitsluiten. Honden met heupdysplasie kunnen een abnormale stand vertonen, stijve gang, spieratrofie, verminderde beweeglijkheid van het heupgewricht en pijn bij manipulatie van de heup (Smith et al., 2012; Syrcle, 2017).

Vervolgens kan de diagnose van heupdyplasie bevestigd worden aan de hand van ventrodorsale radiografie met de heupen in extensie (Figuur 4). Heuplaxiteit kan getest worden aan de hand van de test van Ortolani (Figuur 5) of de Barden-test (Smith et al., 2012; Syrcle, 2017). Een andere mogelijkheid om heuplaxiteit te diagnosticeren is door middel van stressradiografie, waarbij er gebruik gemaakt wordt van een "distraction device" (Figuur 6). De distractie-index of laxiteitsindex die vervolgens kan berekend worden is een waarde tussen 0 en 1, waarbij 0 een volledig congruent heupgewricht betekent en 1 luxatie van het gewricht. Het correct uitvoeren van deze stressradiografie en/of de Barden- of Ortolanitest vereisen een (diepe) sedatie (Smith et al., 2012; Broeckx et al., 2018) (Figuur 4, 5, 6).

\section{LEGG-CALVÉ-PERTHES}

Legg-Calvé-Perthes wordt ook soms avasculaire necrose of aseptische necrose van de femurkop genoemd. Er treedt dus avasculaire necrose van de femurkop op die gekarakteriseerd wordt door een nietinflammatoire lokale ischemie en daardoor ontstaat er een vervorming van de femurkop en -nek (Towle en Breur, 2018).

De aandoening Legg-Calvé-Perthes komt meestal voor bij kleine hondenrassen, waarbij miniatuurrassen en terriërs gepredisponeerd zijn (Demko et al., 2005; Towle en Breur, 2018). Aangezien er een duidelijke raspredispositie is, zijn er indicaties dat een erfelijke factor aan de basis van de aandoening ligt. Bijvoorbeeld bij de minipoedel en de west highland white terriër wordt deze aandoening autosomaal recessief overgeërfd. Ook bij manchester terriërs is de erfelijkheid van deze aandoening bekend. (TowleMillard en Breur, 2018)

De meeste patiënten worden aangeboden met klachten rond de leeftijd van vier tot elf maanden. In 12 tot $16,5 \%$ van de gevallen komt de aandoening bilateraal voor. Mannelijke en vrouwelijke dieren hebben even vaak de aandoening (Demko en McLaughlin, 2005; Towle-Millard en Breur, 2018). In milde gevallen kan de aandoening subklinisch zijn. In meer ernstige gevallen ontstaan er klachten van manken die kunnen variëren van intermitterend manken tot het lopen op drie poten. Bij het orthopedisch onderzoek kan er pijn opgemerkt worden bij flexie en/of extensie van het heupgewricht en eventueel ook crepitatie waargenomen worden (Towle-Millard en Breur, 2018). De diagnose kan vervolgens bevestigd worden aan de hand van een ventrodorsale radiografische opname (Figuur 7). Vroege radiografische veranderingen zijn een verhoogde opaciteit van de laterale epifyseale zone van de femurkop en focale lyse van het bot. In een later 
stadium is er afplatting van de femurkop gecombineerd met een gemotteld aspect van de femurkop waar te nemen. Dit evolueert verder naar collaps van de femurkop en verdikking van de femurnek en finaal naar een fractuur van de femurnek (Demko en McLaughlin, 2005). Belangrijke differentiaaldiagnoses zijn infectie en neoplasie maar ook knieproblemen, zoals een ruptuur van de voorste kruisband of patellaluxatie, kunnen gelijkaardige klinische klachten veroorzaken.

Bij voorkeur wordt een chirurgische behandeling aangeraden, aangezien een conservatieve behandeling met rust en pijnmedicatie slechts succesvol is in minder dan $25 \%$ van de gevallen. Chirurgische behandeling aan de hand van een femurkop- en nekexcisie of een heupprothese geeft een gunstig resultaat in 84 tot $100 \%$ van de gevallen (Demko en McLaughlin, 2005; Towle-Millard en Breur, 2018).

\section{HEUPLUXATIE}

Luxatie van de heup treedt bij de hond meestal unilateraal op ten gevolge van een extern trauma. In 59 tot $83 \%$ van de gevallen is dit te wijten aan een aanrijding door een voertuig (DeCamp et al., 2016). Wanneer een hond aangeboden wordt met luxatie is het dan ook zeer belangrijk om na te gaan of er concomitante verwondingen zijn aan het bekken, het sacrum of inwendige structuren zoals de blaas. Door de verplaatsing van de femurkop is op zijn minst een gedeelte van het gewrichtskapsel en ligamentum capitis femoris gescheurd. Bij meer uitgesproken trauma kan er eveneens schade zijn aan de gluteus spieren of het gewrichtskraakbeen van de femurkop en/ of het acetabulum. De typische algemene klachten van deze honden zijn tekenen van pijn, een abnormale stand van het achterste lidmaat, crepitatie bij manipulatie en een verminderde of abnormale beweeglijkheid van het heupgewricht.

In de overgrote meerderheid van de gevallen $(78 \%$ van de honden) treedt er craniodorsale luxatie op, waarbij de femurkop zich craniaal en dorsaal van het acetabulum bevindt (DeCamp et al., 2016). Door deze verplaatsing kan een aantal typische bijkomende uitwendige symptomen opgemerkt worden: het lidmaat wordt korter, er ontstaat een adductie van het dijbeen met een inwaartse rotatie van de knie en een uitwaartse rotatie van de tarsus.

Andere mogelijke luxaties komen slechts in uitzonderlijke gevallen voor. Caudodorsale luxatie is waarschijnlijk eerder een craniodorsale luxatie met een hoge graad van instabiliteit en ventrale luxatie kan geassocieerd zijn met een indeukingsfractuur van het acetabulum. Deze klinische diagnose kan bevestigd worden door middel van een radiografische opname. Hierbij is het van belang om na te gaan of er concomitante verwondingen aanwezig zijn of factoren die een gesloten reductie van de luxatie zouden bemoeilijken of onmogelijk maken, zoals een fractuur van het

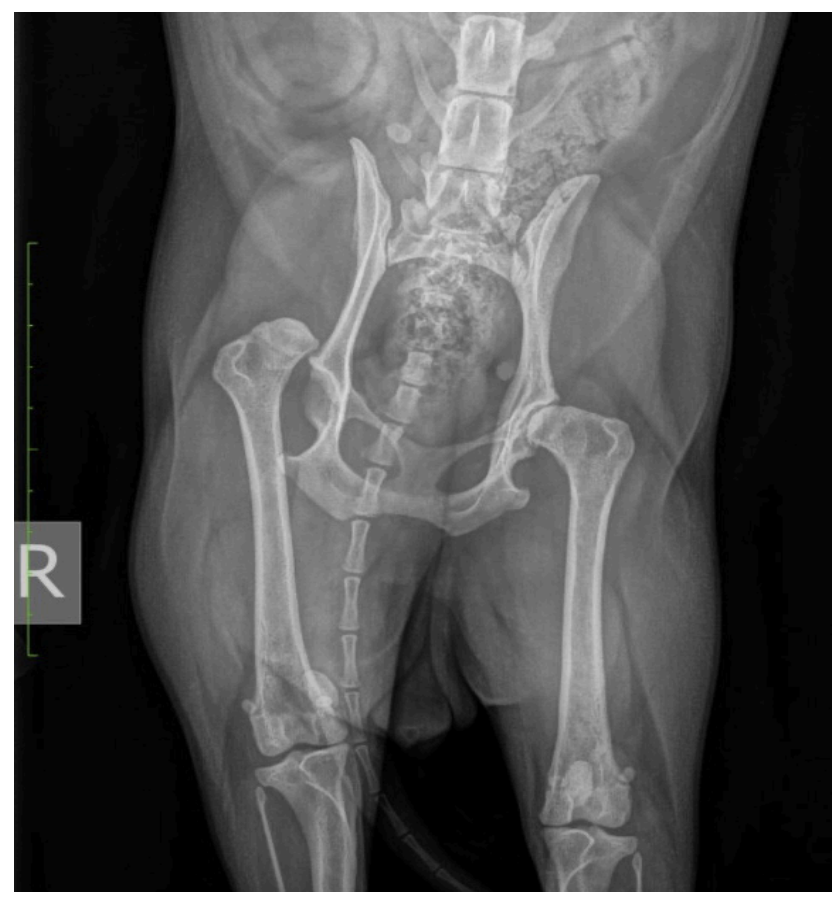

Figuur 9. Chihuahua met bilaterale heupdysplasie die na zeer beperkt trauma zijn rechter heup luxeerde. Let op de typische craniodorsale positie van de femurkop. Wegens de onderliggende dysplasie is conservatieve behandeling hier niet mogelijk.

acetabulum, een fractuur ter hoogte van de femurkop of de femurhals en onderliggende heupdysplasie.

Gesloten reductie kan geprobeerd worden binnen de eerste vier à vijf dagen na het optreden van de heupluxatie. Deze reductie wordt uitgevoerd onder algemene anesthesie en het succespercentage na één poging bedraagt ongeveer $50 \%$ (DeCamp et al., 2016). Afhankelijk van de verwachte mobiliteit van de hond kan postoperatief een Ehmersling geplaatst worden (Figuur 8). In ongeveer 43\% van de gevallen treedt er reluxatie op na een initieel succesvolle reductie en is een chirurgische ingreep zoals een open reductie, heupprothese of femurkopexcisie noodzakelijk (Schlag et al., 2019) (Figuur 9).

\section{CHIRURGISCHE OPTIES}

Wanneer honden met klinische symptomen niet reageren op een conservatieve behandeling kan een chirurgische interventie uitkomst bieden. Vroeger was de enige chirurgische behandeling van een heupprobleem bij kleine hondenrassen een femurkop en -nekexcisie. Een fermurkop en -nekexcisie bij miniatuur- en kleine hondenrassen wordt beschouwd als betrouwbaarder met een klinisch betere uitkomst dan bij grote hondenrassen (Lippincott, 1992).

\section{Femurkop en -nekexcisie (FNE)}

Een FNE-procedure wordt beschouwd als een "salvage" procedure, waarbij het doel is om bot-op-bot- 

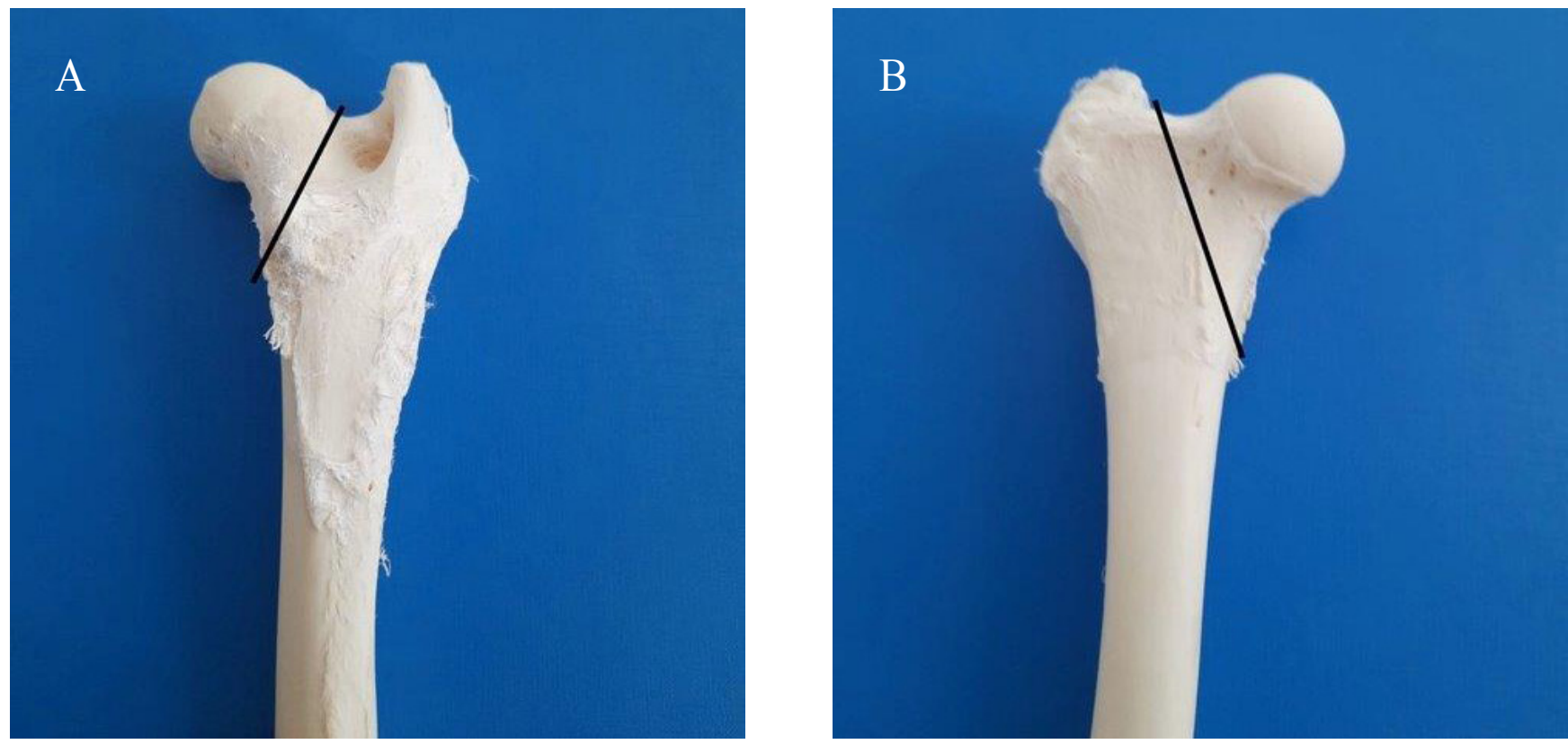

Figuur 10. A. Lateraal en B. mediaal zicht van de ostectomierichting bij een femurkop- en nekexcisie op een anatomisch preparaat.

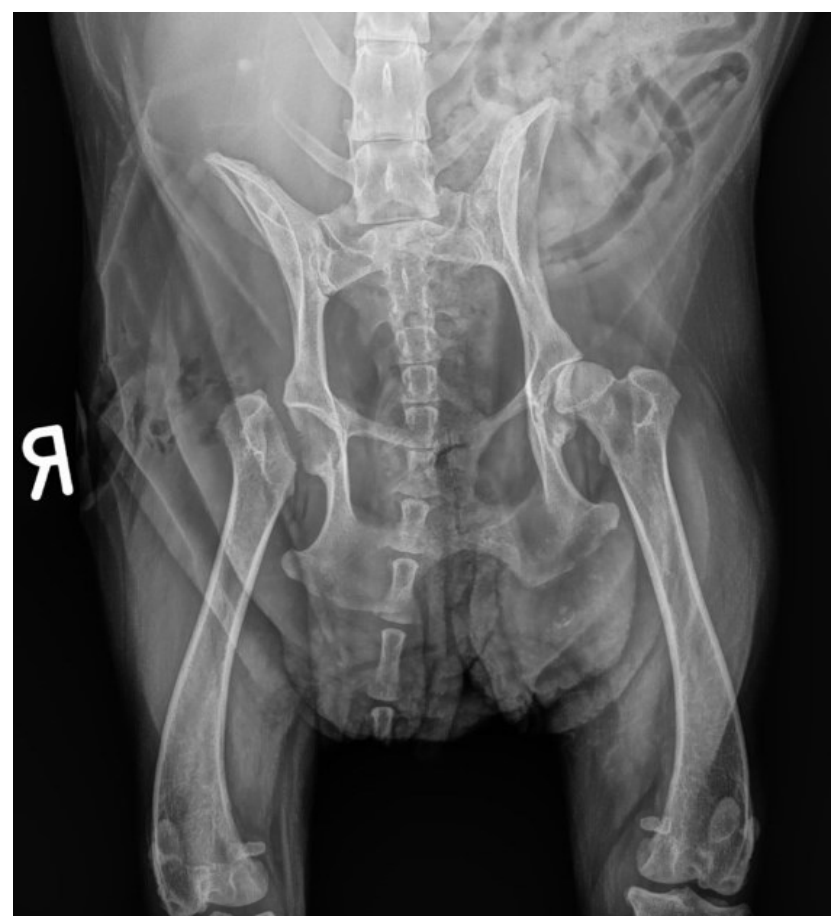

Figuur 11. Femurkop- en nekexcisie van het rechter heupgewricht bij een cavalier king charles. Bemerk de uitgesproken secundaire degeneratieve veranderingen van het linker heupgewricht.

contact tussen femurkop en acetabulum te beperken (Harper, 2017). Er wordt een vals gewricht gevormd (pseudoartrose) bestaande uit dens fibreus weefsel. Door een FNE wordt pijn secundair veroorzaakt door osteoartrose opgeheven en verhoogt de levenskwaliteit. In principe kan een FNE uitgevoerd worden bij kleine hondenrassen van elke grootte, echter geldt dat hoe kleiner de patiënt hoe beter het resultaat zal zijn (Duff en Campbell, 1977). De belangrijkste motivatie voor een eigenaar om voor een FNE te kiezen zijn financiële beperkingen en de kans op erge complicaties bij een heupprothese. De belangrijkste aandachtspunten bij het uitvoeren van deze techniek zijn:

- De heup moet geluxeerd kunnen worden. Hierbij kan het nodig zijn om het ligamentum capitis femoris door te halen met een "Hatt spoon" of mayoweefselschaar.

- Het craniale oppervlak van de proximale femur moet zichtbaar zijn om een correcte ostectomie te kunnen uitvoeren. Hiervoor moet de poot $90^{\circ}$ extern geroteerd worden zodat het craniale oppervlak van de femur parallel met de tafel is en de patella naar het plafond gericht is.

- De ostectomie wordt uitgevoerd op de lijn tussen de femurnek en de femurmetafyse; het begin is juist mediaal van de trochanter major en is dan naar caudomediaal gericht om juist proximaal van de trochanter minor te eindigen (Vezzoni en Peck, 2018) (Figuur $10 \mathrm{~A}$ en B). Na verwijdering van de femurkop en -nek wordt de zaagsnede gepalpeerd op onregelmatigheden. Frequent wordt een schel van de femurnek aan het caudale oppervlak van de femur gevonden, omdat de zaag loodrecht op de chirurgietafel wordt geplaatst. Deze kan schuren tegen de acetabulumrand, waardoor de vorming van fibrous weefsel tussen de botten ("pseudoartrose") kan worden verhinderd. Onregelmatigheden kunnen weggenomen worden met een rongeur of botrasp. Het is belangrijk de poot proximaal en distaal te bewegen om aanwezigheid van crepitatie te kunnen detecteren.

- Postoperatief wordt radiografisch nagegaan of er voldoende femurnek is weggenomen en of er geen fracturen zijn ter hoogte van de trochanter major of femur (Figuur 11). 
Een FNE kan bilateraal worden uitgevoerd, waarbij idealiter de tweede zijde na acht à tien weken wordt uitgevoerd. Echter, in geval van erge bilaterale heupdysplasie (HD) kunnen beide zijden tijdens eenzelfde anesthesie ook simultaan uitgevoerd worden. In een studie van Rawson et al. (2005) met vijftien honden $(19-30,9 \mathrm{~kg})$ die een bilaterale FNE ondergingen ten gevolge van erge bilaterale HD werd aangetoond dat alle honden vier dagen postoperatief terug konden stappen.

In tegenstelling tot de meeste orthopedische ingrepen zijn strikte hokrust en beperkte activiteit tegenaangewezen na een FNE. Het is aangeraden dat patiënten die een FNE hebben ondergaan, zo snel en frequent mogelijk de geopereerde poot gebruiken om de beweeglijkheid van het heupgewricht te bevorderen en spieratrofie te vermijden. Multimodaal postoperatief pijnmanagement is hier zeer belangrijk. Naast een niet-steroïdaal anti-inflammatoir geneesmiddel en andere analgetica is een georganiseerd rehabilitatieprogramma essentieel.

De belangrijkste complicaties die gezien worden bij een FNE zijn verkorting van de poot, beschadiging van de ischiadicuszenuw, patellaluxatie, spieratrofie, verminderde beweeglijkheid van de heup en de aanwezigheid van pijn en manken.

\section{Heupprothese}

Een heupprothese is een algemeen aanvaarde chirurgische techniek voor coxofemorale osteoartrose bij grote hondenrassen. Het vermindert pijn ter hoogte van het aangetaste heupgewricht en bevordert het functioneren ervan met gerapporteerde succespercentages van 92-98\% (Olmstead et al., 1983). Met de ontwikkeling van een miniatuurheupprothese-systeem wordt een heupprothese ook toegankelijk voor miniatuur- en kleine hondenrassen en kan een degelijk alternatief aangeboden worden voor conservatieve therapie en FNE. In een studie van Warnock et al. (2003) werd het gebruik van het "Cemented BioMedtrix Modular MPS System" bij zeventien honden van 12 tot $25 \mathrm{~kg}$ onderzocht. Er werd gebruik gemaakt van een maat 4 cobalt-chroom-femurstem, een $18 \mathrm{~mm}$-diameter acetabulumcup en een $12 \mathrm{~mm}$-femurkop. Tijdens chirurgie traden er vijf complicaties op: iatrogene fissuur van de proximale femurcortex, perforatie van de acetabulaire cortex en verplaatsing van de acetabulaire cup na cementering. Er werd een succespercentage van $83 \%$ genoteerd (goed tot excellent). De belangrijkste postoperatieve complicaties (bij 22\% van de gevallen) waren craniodorsale luxatie, acetabulaire cupverplaatsing en aseptische loslating van het femur implantaat.

Sinds 2005 is het "BioMedtrix Modular Micro THR Implantation System" beschikbaar voor kleine honden en katten $(<12 \mathrm{~kg})$. In een studie van Liska (2010) werd dit systeem toegepast bij 49 honden en 8 katten van 2 tot $15 \mathrm{~kg}$. Er waren twee femurstemmaten beschikbaar (nr 2 en 3). Er was een acetabulumcup van polyethyleen met ultrahoog moleculair gewicht, met een 12,14 , of $16 \mathrm{~mm}$-buitendiameter en een $8 \mathrm{~mm}$ binnendiameter beschikbaar en er werd een femurkop van $8 \mathrm{~mm}$ gebruikt. Er werd een succespercentage van 91\% genoteerd. Intra- of postoperatieve complicaties traden op bij $18 \%$ van de dieren en waren voornamelijk luxaties. In een studie van Marino et al. (2012) werd tot gelijkaardige conclusies gekomen (Marino et al., 2012).

Voor miniatuurrassen werd in 2011 een nanoheupprothesesysteem beschreven voor twaalf honden van 2,5 tot $5,9 \mathrm{~kg}$. (Ireifej et al., 2012) Bij dit systeem vormde de stem één geheel met een $6 \mathrm{~mm}$-femurkopen articuleerde met een 10mm-acetabulumcup, gemaakt van cobalt-chroom en polyethyleen met ultrahoog moleculair gewicht. Voor alle twaalf honden werd uiteindelijk een goed tot excellent resultaat bekomen, alhoewel er bij 33\% ook significante postoperatieve complicaties waren, namelijk femurfractuur en verplaatsing van de acetabulum component.

\section{FYSIOTHERAPIE - MANAGEMENT VAN HEUP- DYSPLASIE}

Fysiotherapie kan zowel toegepast worden als postoperatieve ondersteuning of als conservatieve behandeling. Zoals reeds besproken zijn de femurkop- en -nekexcisie en de heupprothese de belangrijkste chirurgietechnieken voor de behandeling van een heuppathologie bij kleinere hondenrassen. Fysiotherapie zorgt voor een postoperatieve ondersteuning en bevordert het herstel van patiënten die dergelijke chirurgie ondergingen.

Het eerste doel van het rehabilitatieproces is gericht op de beheersing van pijn en ontsteking. Bij een heupprothese geldt een strikte bewegingsbeperking gedurende de eerste vier tot zes weken van de herstelperiode (Millis en Levine, 2014). Tijdens de eerste drie weken na de operatie is het toedienen van aangepaste medicatie, zoals NSAID's, aangewezen.

Opioïden, zoals tramadol, kunnen de eerste drie tot zeven dagen postoperatief bijkomstig aangewend worden. Cryotherapie, die toegepast wordt om postoperatieve ontsteking te temperen, induceert vasoconstrictie en zorgt voor een verminderde doorbloeding en zwelling, verminderde enzymatische weefselschade en pijnstilling. "Cold-packs" dienen gedurende de eerste 24 tot 48 uur om de vier uur gedurende twintig minuten op de operatiewonde aangebracht te worden (Millis en Levine, 2014).

Het tweede doel van het rehabilitatieproces is gericht op het verbeteren van de beweeglijkheid en het bewegingsbereik ("range of motion") van de heup. De manuele therapieën massage en stretchen zijn hiervoor aangewezen. Passieve "range of motion" (PROM) is een veelgebruikte techniek, waarbij het gewricht een maximale fysiologische beweging uitvoert zonder 
spierspanning te gebruiken. Deze techniek kan uitgevoerd worden in de initiële postoperatieve fase van elke bovenvermelde chirurgie en eveneens tijdens het ontwaken na een femurkop en -nekexcisie (Millis en Levine, 2014).

Het herstel van de functionaliteit van de poot is het derde doel van het rehabilitatieproces. Om functioneel herstel te bewerkstelligen, dient de patiënt actieve oefeningen uit te voeren. De moeilijkheidsgraad van dergelijke oefeningen dient geleidelijk opgedreven te worden gedurende de eerste drie maanden na chirurgie (Millis en Levine, 2014). Initiële oefeningen tijdens de postoperatieve fase zijn onder andere geassisteerd stappen, gecontroleerde lage-impactoefeningen, zit-sta-oefeningen en evenwichtsoefeningen. Voor een femurkop en -nekexcisie ligt de nadruk op een goede extensie van de heup, hetgeen bekomen wordt door dansoefeningen en wandelen op hellingen. Gedurende de tweede fase van het herstel worden oefeningen in de onderwaterloopband aangeraden voor elk type heupoperatie (Millis en Levine, 2014).

Alle bovenvermelde behandelingen kunnen ook als conservatieve therapie ingezet worden. Additioneel kunnen lasertherapie, ultrasoontherapie, thermotherapie, elektrische stimulatie (TENS), voedingssupplementen (voornamelijk chondroprotectiva en omega-3 vetzuren) en een aangepast dieet opgenomen worden in het behandelingsplan (Millis en Levine, 2014).

\section{REFERENTIES}

Broeckx B. J. G., Vezzoni A., Bogaerts E., Bertal M., Bosmans T., Stock E., Deforce D., Peelman L., Saunders J. H. (2018). Comparison of three methods to quantify laxity in the canine hip joint. Veterinary and Comparative Orthopaedics and Traumatology 31, 23-29

Coopman F., Verhoeven G., Saunders J., Duchateau L., Van Bree H., Duchateau L. (2008). Prevalence of hip dysplasia, elbow dysplasia and humeral head osteochondrosis in dog breeds in Belgium. Veterinary Record 163, 654658

DeCamp C. E., Johnston S. A., Déjardin L. M., Schaefer S. L. (2016). In: Brinker, Piermattei, and Flo's Handbook of Small Animal Orthopaedics and Fracture Repair. Fifth edition, Elsevier, Missouri, 468-480

Demko J., McLaughlin R. (2005). Developmental orthopedic disease. Veterinary Clinics of North America. Small Animal Practice 35, 1111-1135

Duff R., Campbell J. R. (1977). Long-term results of excision arthroplasty of canine hip. Veterinary Record 101, 181-184

Harper T. A. M. (2017). Femoral head and neck excision. Veterinary Clinics of North America-Small Animal Practice 47, 885-897

Ireifej S., Marino D., Loughin C. (2012). Nano total hip replacement in 12 dogs. Veterinary Surgery 41, 130-135

King M. D. (2017). Etiopathogenesis of canine hip dysplasia, prevalence, and genetics. Veterinary Clinics of North America-Small Animal Practice 47, 753-767

Lippincott C. L. (1992). Femoral head and neck excision in the management of canine hip dysplasia. Veterinary Clinics of North America. Small Animal Practice 22, 721-737

Marino D. J., Ireifej S. J., Loughin C. A. (2012). Micro total hip replacement in dogs and cats. Veterinary Surgery 41, 121-129

Martin S. W., Kirby K., Pennock P. W. (1980). Canine hipdysplasia - breed effects. Canadian Veterinary JournalRevue Veterinaire Canadienne 21, 293-296

Millis D., Levine D. (2014). In: D. Millis and D. Levine (editors). Canine Rehabilitation and Physical Therapy. Second edition, Elsevier Health Sciences, Philadelphia.

Moores A. (2006). Decision making in the management of hip luxations in dogs and cats. In Practice 28, 570-576

Olmstead M. L., Hohn R. B., Turner T. M. (1983). A 5-year study of 221 total hip replacements in the dog. Journal of the American Veterinary Medical Association 183, 191194

Rawson E. A., Aronsohn M. G., Burk R. L. (2005). Simultaneous bilateral femoral head and neck ostectomy for the treatment of canine hip dysplasia. Journal of the American Animal Hospital Association 41, 166-170

Rettenmaier J. L., Keller G. G., Lattimer J. C., Corley E. A., Ellersieck M. R. (2002). Prevalence of canine hip dysplasia in a veterinary teaching hospital population. Veterinary Radiology \& Ultrasound 43, 313-318

Schlag A. N., Hayes G. M., Taylor A. Q., Kerwin S. C., Dugat D. R., Vitt M. A., Stratton D. T., Duffy D. J. (2019). Analysis of outcomes following treatment of craniodorsal hip luxation with closed reduction and Ehmer sling application in dogs. Journal of the American Veterinary Medical Association 254, 1436-1440

Smith G. K., Karbe G. T., Agnello K. A., McDonald-Lynch M. B. (2012). Pathogenesis, diagnosis and control of canine hip dysplasia. In: K.M. Tobias and S.A. Johnston (editors). Veterinary Surgery: Small Animal. St. Louis, Mo., p. 824-848.

Syrcle J. (2017). Hip dysplasia clinical signs and physical examination findings. Veterinary Clinics of North America-Small Animal Practice 47, 769-775

Towle-Millard H. A., Breur G. (2018). Miscellaneous orthopedic conditions. In: S. Johnston and K.M. Tobias (editors). Veterinary Surgery: Small Animal. Second edition. Vol 1, St Louis (MO), p. 1309.

Vezzoni A., Peck J. N. (2018). Surgical management of hip dysplasia. In: S.A. Johnston and K.M. Tobias (editors). Veterinary Surgery: Small Animal Expert Consult. Second edition, Vol 1, St Louis (MO), p. 1016-1018.

Warnock J. J., Dyce J., Pooya H., Schulz K. S. (2003). Retrospective analysis of canine miniature total hip prostheses. Veterinary Surgery 32, 285-291

Witsberger T. H., Villamil J. A., Schultz L. G., Hahn A. W., Cook J. L. (2008). Prevalence of and risk factors for hip dysplasia and cranial cruciate ligament deficiency in dogs. Journal of the American Veterinary Medical Association 232, 1818-1824

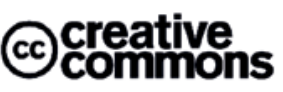

C) 2020 by the authors. Licensee Vlaams Diergeneeskundig Tijdschrift, Ghent University, Belgium. This article is an open access article distributed under the terms and conditions of the Creative Commons Attribution (CC BY) license (http://creativecommons.org/licenses/by/4.0/). 